\title{
Ubiquitin-specific protease as the underlying gene biomarker for aortic stenosis
}

\author{
Yin Yang ${ }^{\dagger}$, Lian-qun Wang ${ }^{\dagger}$, Bo-chen Yao $^{\dagger}$ and Zhi-gang Guo
}

\begin{abstract}
Background: Aortic stenosis is a common heart valvular disease whose pathological processes include an inflammatory reaction and lipid accumulation. However, its detailed pathogenesis is yet to be completely elucidated. Therefore, it is of great significance to further explore the molecular mechanisms of aortic stenosis.

Methods: Four datasets were downloaded from the Gene Expression Omnibus (GEO) database. Firstly, the differently expressed genes (DEGs) were screened between control and aortic stenosis samples. Secondly, weighted gene co-expression network analysis (WGCNA) was performed to find the highly relevant gene modules. Enrichment analysis and protein-protein interaction (PPI) networking were also performed, then Cytoscape was used to identify hub genes. Finally, the six participants (3 control participants and 3 patients with aortic stenosis) were recruited at the Tianjin Chest Hospital. In order to verify the expression level of USP14, several molecular experiments were performed, including hematoxylin-eosin (HE) staining, immunohistochemistry, immunofluorescence technology, real time-quantitative polymerase chain reaction (RT-qPCR), and western blotting.

Results: A total of 9636 DEGs were found between the control and aortic stenosis samples. The DEGs were mainly enriched in the autophagy-animal, cellular lipid catabolic process, apoptosis, and glycoside metabolic process categories. Eleven hub genes were identified via four different algorithms. Following verification of the patient samples, Ubiquitin-specific protease 14 (USP14) was found to be displayed at higher levels in the aortic stenosis samples.

Conclusion: USP14 might be involved in the occurrence and development of aortic stenosis, so it would be a molecular target for early diagnosis and specific treatment of aortic stenosis. There is a significant association between the high expression of USP14 and aortic stenosis, indicating that this gene may be a genetic risk factor for aortic stenosis.
\end{abstract}

Keywords: Aortic stenosis, Ubiquitin-specific protease 14, Gene biomarker, Bioinformatics analysis, Lipid metabolism

\footnotetext{
* Correspondence: gzg8967@163.com

†Yin Yang, Lian-qun Wang and Bo-chen Yao contributed equally to this work. Department of Cardiac Surgery, Tianjin Chest Hospital, No. 261 South

Taierzhuang Road, Jinnan District, Tianjin 300222, China
}

(c) The Author(s). 2020 Open Access This article is licensed under a Creative Commons Attribution 4.0 International License, which permits use, sharing, adaptation, distribution and reproduction in any medium or format, as long as you give appropriate credit to the original author(s) and the source, provide a link to the Creative Commons licence, and indicate if changes were made. The images or other third party material in this article are included in the article's Creative Commons licence, unless indicated otherwise in a credit line to the material. If material is not included in the article's Creative Commons licence and your intended use is not permitted by statutory regulation or exceeds the permitted use, you will need to obtain permission directly from the copyright holder. To view a copy of this licence, visit http://creativecommons.org/licenses/by/4.0/ The Creative Commons Public Domain Dedication waiver (http://creativecommons.org/publicdomain/zero/1.0/) applies to the data made available in this article, unless otherwise stated in a credit line to the data. 


\section{Background}

Aortic stenosis (AS) is a common heart valvular disease [1]. In recent years, the incidence of AS has been on the rise. Apart from its degenerative, congenital (bicuspid valve), and inflammatory causes, AS might also be caused by rheumatic heart disease and other less common diseases, such as Paget's disease, Fabry disease, and lupus erythematosus. The diagnosis of aortic stenosis is based on an echocardiographic assessment [2]. The valve area is $3-4 \mathrm{~cm}^{2}$ in healthy adults. In general, AS patients do not exhibit clinical symptoms until the valve area is less than $1.0 \mathrm{~cm}^{2}$. At that point, the extra work required to open the valve prevents the heart from functioning properly. Currently, age-related degenerative aortic stenosis has become the most common cause of aortic stenosis in adults. The prevalence of aortic stenosis increases with age, averaging $0.2 \%$ in people aged 50 to 59 and $9.8 \%$ in people aged 80 to 89 [3].

The pathological process of aortic stenosis includes an inflammatory reaction, lipid accumulation, angiotensin converting enzyme activation, and macrophage and $\mathrm{T}$ lymphocyte infiltration. The activity of the valve is limited due to the deposition of calcium at the base of the valve, which leads to aortic stenosis. Aortic valve calcification is similar to coronary heart disease and has a high correlation with coronary artery calcification. Hypertension, dyslipidemia, diabetes, and smoking are the risk factors $[4,5]$.

Aortic stenosis is a slowly progressing disease. Patients with aortic stenosis have a long asymptomatic period; those without symptoms need no treatment but should follow-up regularly. However, when symptoms appear or obstruction becomes very severe, rapid diagnosis and treatment is essential [6]. At present, the treatments for aortic stenosis include surgical aortic valve replacement (AVR) and transcatheter aortic valve implantation (TAVI) [7]. In fact, sometimes patients are referred to AVR after the myocardium has started to decompensate, which might cause new tissue damage and lead to serious complications. Thus, early diagnosis and prevention are needed. In addition, TAVI is also associated with paravalvular aortic regurgitation, stroke, vascular complications, and the need for a new pacemaker.

Therefore, it is of great clinical significance to further explore the molecular mechanisms of aortic stenosis, in order to find molecular targets for early diagnosis, prevention, and specific treatment. Microarray technology can use genomic data to explore and mine diseaserelated differentially expressed genes. At present, it is an effective method to explore the pathogenesis of diseases [8]. To meet these goals, this paper uses microarray technology to mine the differentially expressed genes between stenotic valves and normal aortic valves, and to identify the hub genes of aortic stenosis. Results are further verified by molecular experiments.

\section{Methods}

\section{Data from the GEO database}

On October 16, 2019, the key words "(aortic valve) AND calcified" were set to detect the datasets, using a filter of "expression profiling by array." There were five inclusion criteria: a sample number of more than ten per dataset (samples of less than ten were excluded), data from Homo sapiens (data from other species were excluded), a series entry type, expression profiling by array (data using methylation profiling by array were excluded), and a diagnosis of aortic stenosis caused by the aortic valve sclerosis or calcification (data from mitral valve stenosis diagnoses were excluded).

The study obtained the transcriptome expression profiles GSE12644 (GPL570 [HG-U133_Plus_2] Affymetrix Human Genome U133 Plus 2.0 Array), GSE51472 (GPL570 [HG-U133_Plus_2] Affymetrix Human Genome U133 Plus 2.0 Array), GSE83453 (GPL10558 Illumina Human HT-12 V4.0 expression beadchip) and GSE88803 (GPL6244 [HuGene-1_0-st] Affymetrix Human Gene 1.0 ST Array [transcript (gene) version]) from the GEO database (Table 1).

\section{Screening of DEGs}

The four GEO series were merged and normalized by the $\mathrm{R}$ packages sva and limma. The DEGs were screened by R package limma; the cut-off criteria were $P$ value < 0.05 and $\log$ [Fold Change (FC) $] \geq 100$ or $\leq-100$.

\section{WGCNA analysis}

WGCNA is an algorithm for mining module information from chip data, which can describe the patterns of genes between microarray samples and find highly relevant gene modules. In this study, WGCNA analysis was conducted by the R package WGCNA. The lowest thresholding power for the scale-free topology fit index was

Table 1 A summary of aortic valve stenosis microarray datasets from different GEO datasets

\begin{tabular}{lllllcc}
\hline & Series & Platform & Affymetrix GeneChip & Samples & Normal & Calcification \\
\hline 1 & GSE12644 & GPL570 & [HG-U133_Plus_2] Affymetrix Human Genome U133 Plus 2.0 Array & 20 & 10 & 10 \\
2 & GSE51472 & GPL570 & [HG-U133_Plus_2] Affymetrix Human Genome U133 Plus 2.0 Array & 15 & 5 & 10 \\
3 & GSE83453 & GPL10558 & Illumina HumanHT-12 V4.0 expression beadchip & 27 & 8 & 10 \\
4 & GSE88803 & GPL6244 & [HuGene-1_0-st] Affymetrix Human Gene 1.0 ST Array [transcript (gene) version] & 10 & 5 & 5 \\
\hline
\end{tabular}


0.9. The ME-Diss Thresh was set at 0.1 to merge similar modules.

\section{Functional annotation of DEGs}

Gene Ontology (GO) (see http://geneontology.org/docs/ introduction-to-go-resource/, version https://doi.org/10. 5281/zenodo.2529950, released January 1, 2019) analysis is an ontology widely used in bioinformatics analysis, containing three aspects of biology: biological processes (BP), cellular components (CC), and molecular functions (MF). The Kyoto Encyclopedia of Genes and Genomes (KEGG) (https://www.genome.jp/kegg/docs/relnote.html, version 92.0, released October 1, 2019) analysis can provide specific pathways and link genomic information with higher-order functional information. Gene Set Enrichment Analysis (GSEA) (version 4.0.2) is a computational method that can execute GO and KEGG analysis with a given gene list. Metascape (http://metascape.org/ gp/index.html\#/main/step1, released August 14, 2019) is an online analysis tool providing a comprehensive gene list annotation and analysis resource. In this study, the GO and KEGG analysis of MEdarkgrey model DEGs were performed by GSEA and Metascape. The $p$-value cutoff was 0.05, with Min Overlap = 3 and Min Enrichment $=1.5$.

\section{Construction and analysis of the PPI network}

STRING (http://string-db.org, Version 11.0), an online database, can predict and provide a PPI network after importing the MEdarkgrey model DEGs. For this analysis, all data sources were considered. The minimum required interaction score was medium confidence (0.400). Cytoscape (Version 3.7.2) is an analysis tool used to provide biological network analysis and two-dimensional (2D) visualization for biologists. The algorithms which were used for network analysis included a Betweenness algorithm, Radiality algorithm, EcCentricity algorithm, and Closeness algorithm. In this study, the PPI network and hub genes were constructed and analyzed by the STRING database and Cytoscape.

\section{Identification of hub DEGs associated with cardiovascular diseases}

The comparative toxicogenomics database (CTD) (http://ctdbase.org/, released November 6, 2019 [15938]) is a web-based database that can predict the relationship between a gene/protein and disease. Operation instructions are available at http://ctdbase.org/help/. In this study, the relationships between gene products and heart diseases were analyzed by this database.

\section{MiRNA of hub DEGs prediction}

TargetScan (www.targetscan.org, released March 2, 2018) is an online database that performs predictive
Table $\mathbf{2}$ The demographic details of participants

\begin{tabular}{llllll}
\hline Characteristics & & \multicolumn{3}{l}{ Aortic stenosis } & P \\
\cline { 3 - 5 } & & & No & Yes & \\
\hline Sex & Male & 4 & $1(16.7 \%)$ & $3(50.0 \%)$ & 0.083 \\
& Female & 2 & $2(33.3 \%)$ & $0(0.0 \%)$ & \\
Age & & 6 & $58.00 \pm 4.58$ & $65.33 \pm 3.06$ & 0.082 \\
Co-morbidities & No & 1 & $1(16.7 \%)$ & $0(0.0 \%)$ & 0.273 \\
& Yes & 5 & $2(33.3 \%)$ & $3(50.0 \%)$ & \\
\hline
\end{tabular}

Independent-samples T test was used to compare continuous data. Pearson's chi-squared test was used to compare the categorical data. The co-morbidities in this research included hypertension, diabetes, and coronary heart disease. "No" of "Co-morbidities" presented that the participants did not suffer from any of the above three co-morbidities. "Yes" of "Co-morbidities" presented that the participant suffered from all above three co-morbidities

analysis and identifies possible mechanisms for coregulating the expression of hundreds of genes expressed in different cell types. In this study, TargetScan was used to screen for miRNAs that regulate the hub DEGs.

\section{Functional annotation of miRNA}

DIANA-miRPath v3.0 (http://www.microrna.gr/miRPathv3, version 3) is an online analysis tool suite dedicated to conducting functional and pathway enrichment analysis for miRNA. In this study, GO and KEGG pathway enrichment analysis were performed using miRPath $(P<0.05)$.

\section{Statistical analysis}

The analyses in this study were performed using Perl, $\mathrm{R}$ (version 3.5.3), and SPSS 20.0 (SPSS Inc., Chicago, IL, USA). The hub DEGs and their effect on aortic stenosis, based on univariate logistic proportional regression analysis and multivariate logistic proportional regression analysis, were analyzed via SPSS 20.0. Finally, the relative operating characteristic (ROC) curve was provided by SPSS 20.0 and MedCalc software (MedCalc Software Ltd., Ostend, Belgium).

\section{Participants and ethics}

At the Tianjin Chest Hospital, the pathological sections were obtained between 2018 and 2019 from six participants. The inclusion criteria included being between 18 and 80 years old, a diagnosis of aortic stenosis, and a non-surgical history. Patients whose poor cardiac

Table 3 Primers and their sequences for PCR analysis

\begin{tabular}{ll}
\hline Primer & Sequence $\left(5^{\prime}-3^{\prime}\right)$ \\
\hline ACTIN-hF & CACCCAGCACAATGAAGATCAAGAT \\
ACTIN-hR & CCAGTITTAAATCCTGAGTCAAGC \\
USP14-hF & TGTGCCTGAACTCAAAGATGCC \\
USP14-hR & ACTGTCCTTGTTCACCTITCTCG \\
\hline
\end{tabular}


function, pulmonary function, or liver and kidney function made them unable to tolerate surgery were excluded.

The diagnosis of aortic stenosis was based on the preoperative surface echocardiography, intraoperative esophageal echocardiography, and intraoperative findings [6]. The pathological report manifested that a total of 3 participants were diagnosed with aortic stenosis while 3 others were not. The demographic details of the participants are shown in Table 2. The research conformed to the Declaration of Helsinki, and it was authorized by the Human Ethics and Research Ethics Committees of the Tianjin Chest Hospital. Informed consent was provided by all the participants.

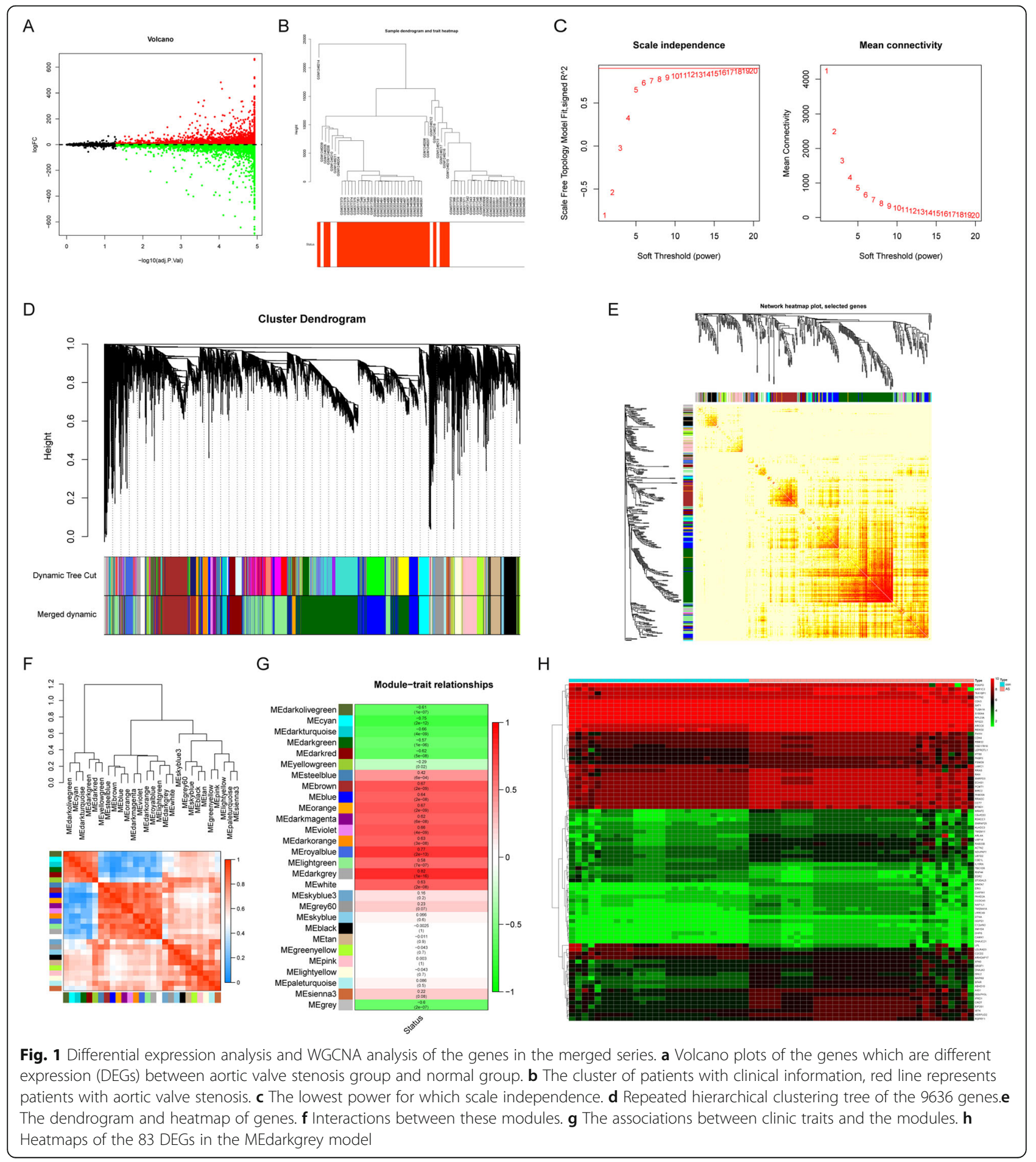



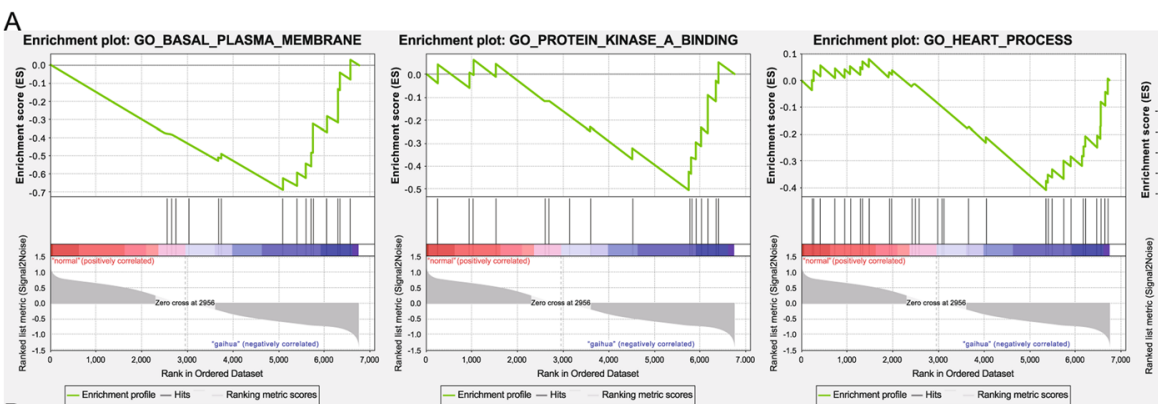

Enrichment plot:

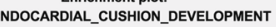

B 1 Enrichment plot: KEGG_GLUTATHIONE_METABOLISM
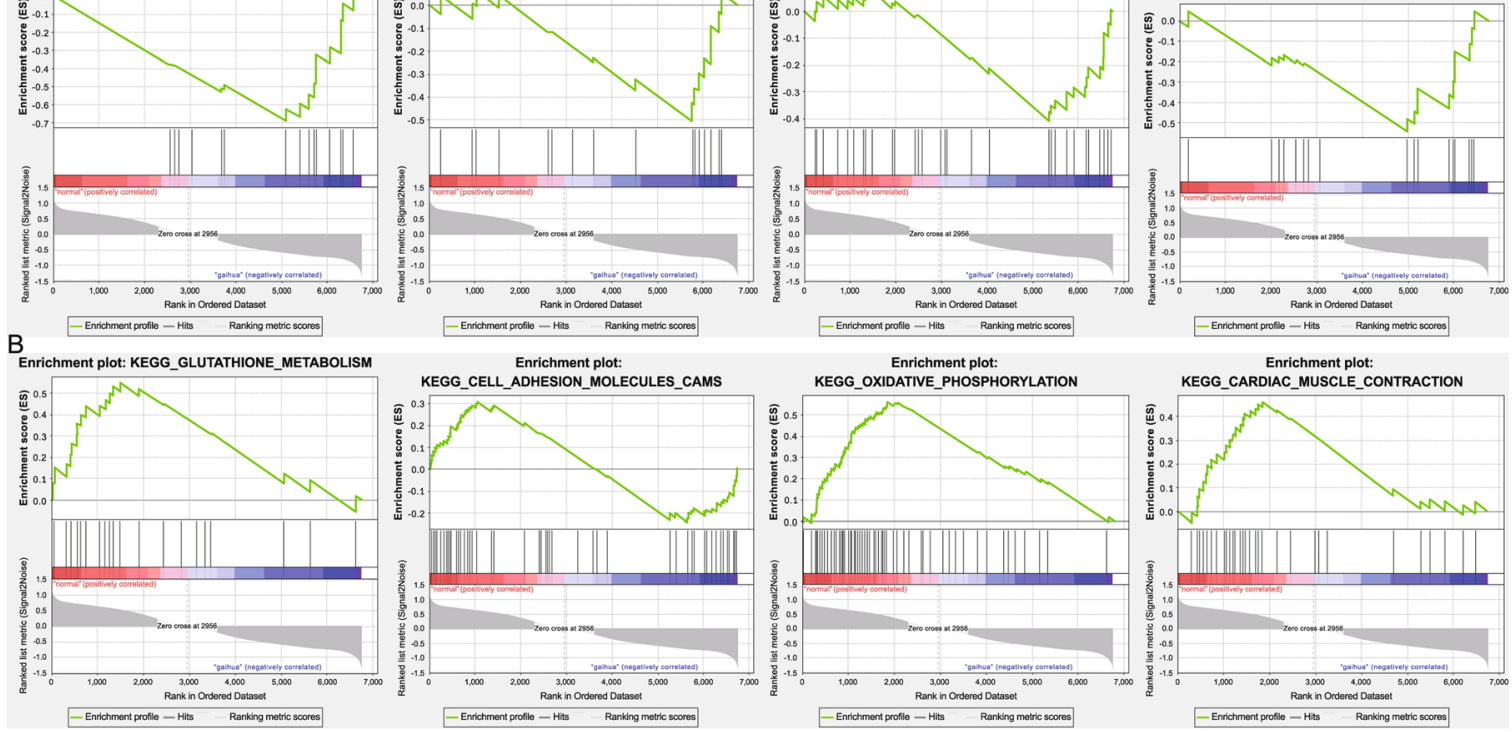

C
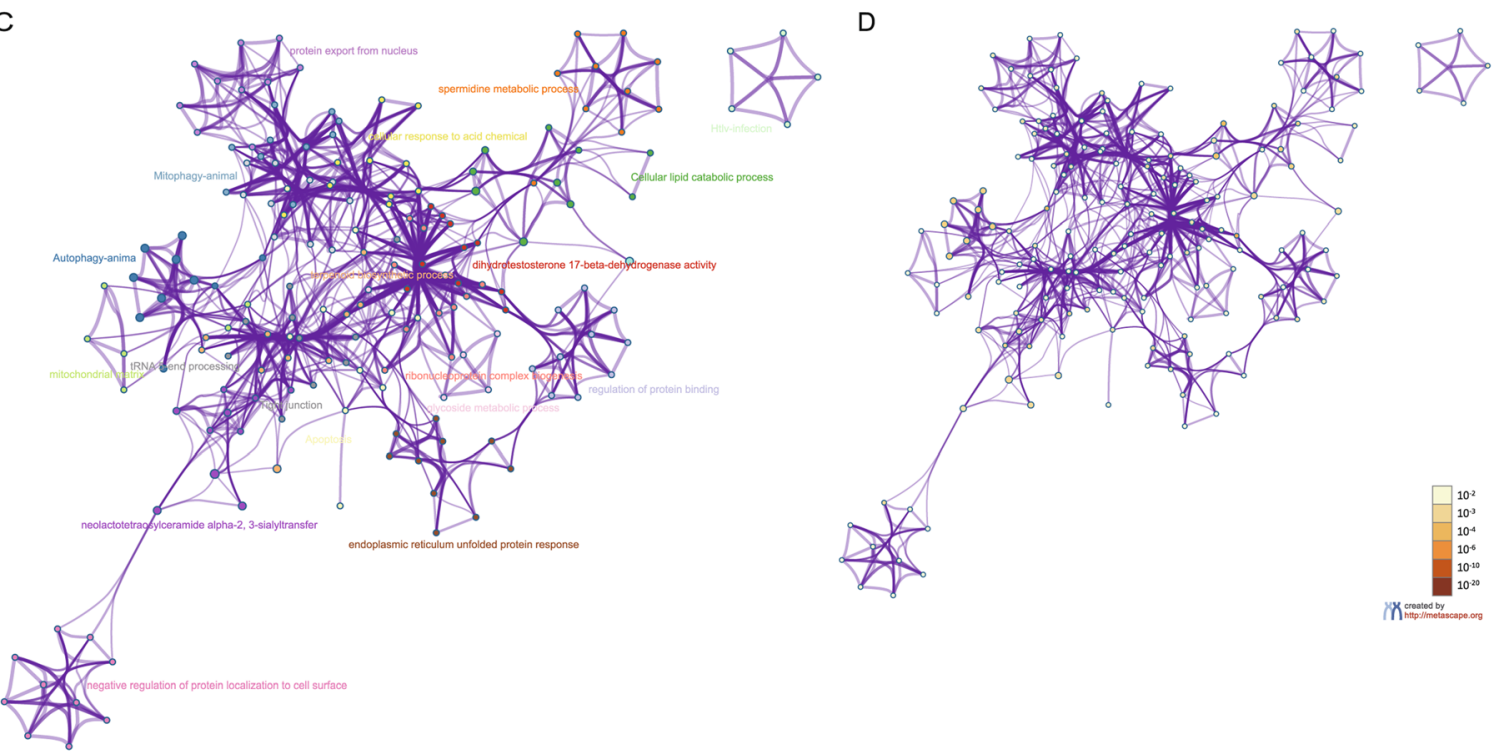

E

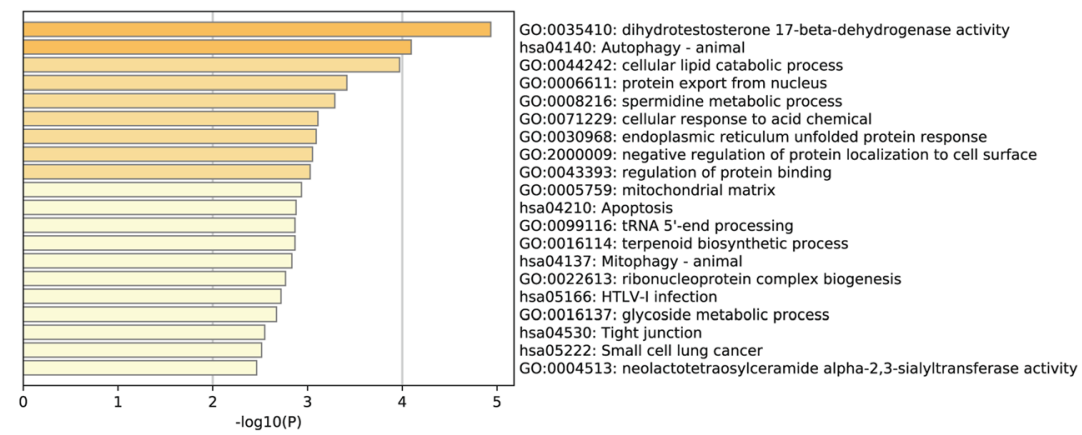

Fig. 2 Gene functional enrichment analysis of the MEdarkgrey model DEGs by GSEA and Metascape. a Gene ontology (GO) analyses by GSEA. b Kyoto Encyclopedia of Genes and Genomes (KEGG) analyses of by GSEA. c Enrichment_GO-KEGG_ColorByCluster analyses by Metascape. d Enrichment_GO-KEGG_ColorByPValue analyses by Metascape. e Enrichment_heatmap_HeatmapSelected GO-KEGG analyses by Metascape 
Table $4 \mathrm{GO}$ analysis by GSEA

\begin{tabular}{|c|c|c|c|c|c|}
\hline TERM & SIZE & NES & $\mathrm{p}$-val & RANK AT MAX & LEADING EDGE \\
\hline \multicolumn{6}{|l|}{ Up-regulated } \\
\hline $\begin{array}{l}\text { GO_REGULATION_OF_CARDIAC_MUSCLE } \\
\text { CELL_CONTRACTION }\end{array}$ & 18 & -1.67584 & 0.003914 & 1264 & tags $=61 \%$, list $=19 \%$, signal $=75 \%$ \\
\hline GO_HEART_PROCESS & 36 & -1.50175 & 0.037109 & 1395 & tags $=42 \%$, list $=21 \%$, signal $=52 \%$ \\
\hline GO_PROTEIN_KINASE_A_BINDING & 17 & -1.51351 & 0.019841 & 977 & tags $=47 \%$, list $=14 \%$, signal $=55 \%$ \\
\hline GO_ENDOCARDIAL_CUSHION_DEVELOPMENT & 21 & -1.55367 & 0.009862 & 1768 & tags $=52 \%$, list $=26 \%$, signal $=71 \%$ \\
\hline GO_STRUCTURAL_CONSTITUENT_OF_CYTOSKELETON & 42 & -1.6003 & 0.00996 & 1034 & tags $=40 \%$, list $=15 \%$, signal $=48 \%$ \\
\hline \multicolumn{6}{|l|}{ Down-regulated } \\
\hline $\begin{array}{l}\text { GO_MULTICELLULAR_ORGANISMAL_MACROMOLECULE_ } \\
\text { METABOLIC_PROCESS }\end{array}$ & 43 & 1.747944 & 0.012146 & 679 & tags $=51 \%$, list $=10 \%$, signal $=57 \%$ \\
\hline GO_MULTICELLULAR_ORGANISM_METABOLIC_PROCESS & 47 & 1.695392 & 0.014344 & 679 & tags $=47 \%$, list $=10 \%$, signal $=52 \%$ \\
\hline GO_CELL_CHEMOTAXIS & 76 & 1.53365 & 0.031955 & 1128 & tags $=53 \%$, list $=17 \%$, signal $=62 \%$ \\
\hline GO_REGULATION_OF_BONE_REMODELING & 18 & 1.481831 & 0.01145 & 916 & tags $=50 \%$, list $=14 \%$, signal $=58 \%$ \\
\hline GO_REGULATION_OF_STEROL_TRANSPORT & 15 & 1.481576 & 0.059289 & 1346 & tags $=53 \%$, list $=20 \%$, signal $=66 \%$ \\
\hline
\end{tabular}

NES Normalized Enrichment Score

\section{Histopathological examination}

The aortic valve was dissected and cut into parts. Part of the artery was fixed in a $4 \%$ poly-formaldehyde solution and processed for paraffin embedding and sectioning. The aortic valve was cut into 6 - $\mu \mathrm{m}$-thick transverse sections and stained with $\mathrm{HE}$ after fixation in a $4 \%$ polyformaldehyde solution embedded in paraffin wax. Then, the immunohistochemistry and immunofluorescence assays were performed to detect the expression level of USP14.

The samples of the aortic valve were taken to make paraffin sections. The paraffin sections were deparaffinized to water, sealed with $\mathrm{H}_{2} \mathrm{O}_{2}$, and washed with double distilled water. After antigen retrieval, immunohistochemistry was used to detect the USP14. The specific detection steps were performed according to the instructions of the VECTASTAIN ${ }^{\curvearrowleft}$ Elite $^{\curvearrowleft}$ ABC Kit (Vector Laboratories Inc., 30 Ingold Road Burlingame, California, USA), as follows.

First, the antigen-fixed paraffin sections were washed with phosphate buffer solution (PBS) 2-3 times (5 min/ time), then blocked with $10 \%$ goat serum (TransGen Biotech Co., LTD, Beijing, China) at $37^{\circ} \mathrm{C}$ for $20 \mathrm{~min}$. Filter paper was used to remove the serum. The mouse anti-human USP14 polyclonal antibody (dilution rate = 1:3000, SAB1406778, Sigma, St. Louis, USA) was added dropwise and incubated overnight at $4{ }^{\circ} \mathrm{C}$, washed three times with PBS (5 min/time), and incubated with goat anti-mouse monoclonal antibody (dilution rate $=1: 5000$, ab205719, Abcam, Cambridge, UK) at $37^{\circ} \mathrm{C}$ for $1 \mathrm{~h}$. Diaminobenzidine (DAB) was used for color development

Table 5 KEGG analysis by GSEA

\begin{tabular}{|c|c|c|c|c|c|}
\hline TERM & SIZE & NES & p-val & RANK AT MAX & LEADING EDGE \\
\hline \multicolumn{6}{|l|}{ Up-regulated } \\
\hline $\begin{array}{l}\text { KEGG_ARRHYTHMOGENIC_RIGHT_VENTRICULAR_ } \\
\text { CARDIOMYOPATHY_ARVC }\end{array}$ & 40 & -1.38995 & 0.071984 & 1598 & tags $=43 \%$, list $=24 \%$, signal $=55 \%$ \\
\hline KEGG_PEROXISOME & 37 & -1.21825 & 0.236686 & 1355 & tags $=43 \%$, list $=20 \%$, signal $=54 \%$ \\
\hline KEGG_PEROXISOME & 37 & -1.21825 & 0.236686 & 1355 & tags $=43 \%$, list $=20 \%$, signal $=54 \%$ \\
\hline KEGG_GAP_JUNCTION & 50 & -1.20703 & 0.208333 & 1746 & tags $=44 \%$, list $=26 \%$, signal $=59 \%$ \\
\hline KEGG_CALCIUM_SIGNALING_PATHWAY & 67 & -1.12748 & 0.296813 & 1585 & tags $=36 \%$, list $=23 \%$, signal $=46 \%$ \\
\hline \multicolumn{6}{|l|}{ Down-regulated } \\
\hline KEGG_CARDIAC_MUSCLE_CONTRACTION & 32 & 1.191075 & 0.318271 & 1839 & tags $=66 \%$, list $=27 \%$, signal $=90 \%$ \\
\hline KEGG_CYTOKINE_CYTOKINE_RECEPTOR_INTERACTION & 94 & 1.251404 & 0.201942 & 1695 & tags $=55 \%$, list $=25 \%$, signal $=73 \%$ \\
\hline KEGG_GLUTATHIONE_METABOLISM & 23 & 1.371425 & 0.064327 & 1499 & tags $=61 \%$, list $=22 \%$, signal $=78 \%$ \\
\hline KEGG_OXIDATIVE_PHOSPHORYLATION & 76 & 1.331254 & 0.211045 & 1839 & tags $=70 \%$, list $=27 \%$, signal $=95 \%$ \\
\hline KEGG_CELL_ADHESION_MOLECULES_CAMS & 64 & 1.131856 & 0.316602 & 1047 & tags $=39 \%$, list $=16 \%$, signal $=46 \%$ \\
\hline
\end{tabular}


(PBS instead of the primary antibody was used as a negative control). Each paraffin section was photographed in 5 fields and counted [9].

\section{RT-qPCR assay}

Total RNA was extracted by the RNAiso Plus (Trizol) kit (Thermofisher, Massachusetts, USA), then reverse transcribed to cDNA. RT-qPCR was performed using a Light Cycler 4800 System with specific primers for USP14. Table 3 presents the primer sequences. The glyceraldehyde-3-phosphate dehydrogenase (GAPDH) was used as an endogenous control.

\section{Western blotting analysis}

Aortic valve tissues were frozen at $-80^{\circ} \mathrm{C}$. Total protein was isolated in a lysis buffer, resolved by $10 \%$ sodium dodecyl sulfate polyacrylamide gel electrophoresis (SDSPAGE), and transferred onto polyvinylidene fluoride
(PVDF) membranes by electroblotting. After blocking it with the Odyssey blocking buffer (LI-COR, Lincoln, USA) for $1 \mathrm{~h}$, the membrane was incubated with primary antibodies at $4{ }^{\circ} \mathrm{C}$ overnight, and then it was incubated with a horseradish peroxidase-conjugated secondary antibody at $37^{\circ} \mathrm{C}$ for $1 \mathrm{~h}$.

Next, the protein bands were scanned and analyzed with the Odyssey scanner [10]. GAPDH was used as an endogenous control. Mouse anti-human GAPDH polyclonal antibody (dilution rate $=1: 5000$, WH0002597M1, Sigma, St. Louis, USA) was used to detect GAPDH, and the secondary antibody was also goat anti-mouse monoclonal antibody (dilution rate $=1: 5000$, ab205719, Abcam, Cambridge, UK). USP14 protein was detected using a mouse anti-human USP14 polyclonal antibody (dilution rate $=1: 3000$, SAB1406778, Sigma, St. Louis, USA). The secondary antibody was goat anti-mouse monoclonal antibody (dilution rate $=1: 5000$, ab205719,

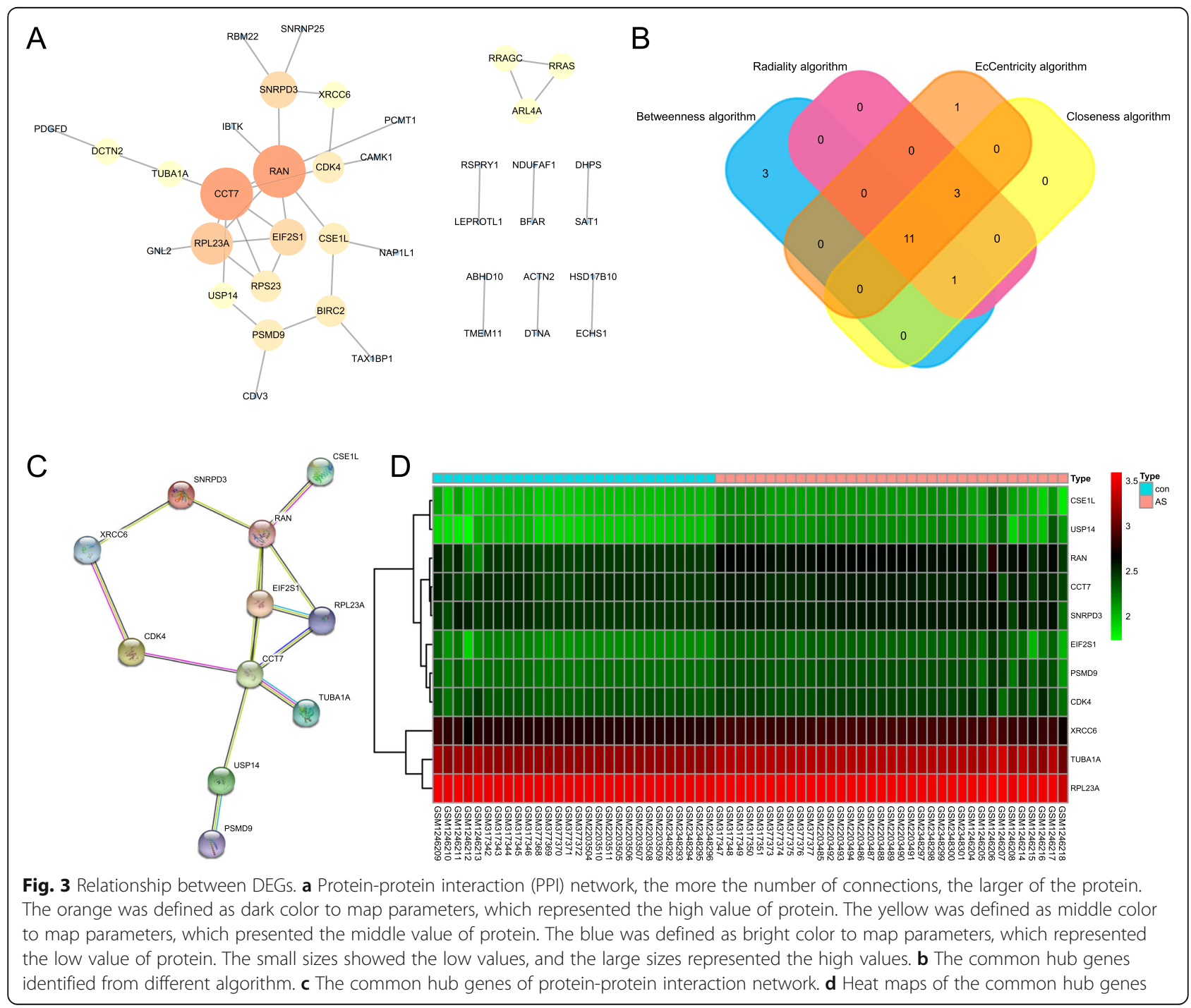


Abcam, Cambridge, UK). The bands were visualized with an enhanced chemiluminescence kit (Millipore, Billerica, Massachusetts, USA) and analyzed with ImagePro Plus 6.0 (Media Cybernetics Inc., Chicago, USA).

\section{Results}

\section{Identification of DEGs}

The merged series contained 5792 up-regulated genes and 3844 down-regulated genes (Fig.1a).

\section{WGCNA analysis and attainment of module DEGs}

In this study, WGCNA analysis was conducted using the $\mathrm{R}$ package WGCNA. The cluster of patients is shown in Fig. 1b. As shown in Fig. 1c, a power value of 8 was the lowest power for which scale independence was below 0.9 , so it was selected to produce a hierarchical clustering tree of the 6301 genes (Fig. 1d). In addition, a dendrogram and heatmap were used to quantify module similarity by correlation (Fig. 1e). Interactions between these modules were then

Table 6 A summary of hub genes

\begin{tabular}{|c|c|c|}
\hline Symbol & Description & Funtion \\
\hline \multirow[t]{3}{*}{ RAN } & \multirow[t]{3}{*}{ RAN, member RAS oncogene family } & GO:0035281 pre-miRNA export from nucleus \\
\hline & & hsa03008: Ribosome biogenesis in eukaryotes \\
\hline & & hsa03013: RNA transport \\
\hline \multirow[t]{3}{*}{ CCT7 } & \multirow[t]{3}{*}{ chaperonin containing TCP1 subunit 7} & GO:1904871 positive regulation of protein localization to Cajal body \\
\hline & & GO:1904869 regulation of protein localization to Cajal body \\
\hline & & GO:1904874 positive regulation of telomerase RNA localization to Cajal body \\
\hline \multirow[t]{3}{*}{ CSE1L } & \multirow[t]{3}{*}{ chromosome segregation 1 like } & GO:0006606 protein import into nucleus \\
\hline & & GO:0006611 protein export from nucleus \\
\hline & & GO:0051170 import into nucleus \\
\hline \multirow[t]{3}{*}{ SNRPD3 } & \multirow{3}{*}{$\begin{array}{l}\text { small nuclear ribonucleoprotein D3 } \\
\text { polypeptide }\end{array}$} & GO:0000387 spliceosomal snRNP assembly \\
\hline & & GO:0008334 histone mRNA metabolic process \\
\hline & & hsa03040: Spliceosome \\
\hline \multirow[t]{3}{*}{ TUBA1A } & \multirow[t]{3}{*}{ tubulin alpha 1a } & GO:0097711 ciliary basal body-plasma membrane docking \\
\hline & & hsa04540: Gap junction; \\
\hline & & hsa04210: Apoptosis \\
\hline \multirow[t]{3}{*}{ USP14 } & \multirow[t]{3}{*}{ ubiquitin specific peptidase 14} & $\begin{array}{l}\text { GO:1903070 negative regulation of ER-associated ubiquitin-dependent protein catabolic } \\
\text { process }\end{array}$ \\
\hline & & GO:1903069 regulation of ER-associated ubiquitin-dependent protein catabolic process \\
\hline & & GO:1904293 negative regulation of ERAD pathway \\
\hline \multirow[t]{3}{*}{ PSMD9 } & \multirow[t]{3}{*}{ proteasome 265 subunit, non-ATPase 9} & GO:0002223 stimulatory C-type lectin receptor signaling pathway \\
\hline & & $\begin{array}{l}\text { GO:0002479 antigen processing and presentation of exogenous peptide antigen via MHC } \\
\text { class I, TAP-dependent }\end{array}$ \\
\hline & & GO:0046676 negative regulation of insulin secretion \\
\hline \multirow[t]{3}{*}{ CDK4 } & \multirow[t]{3}{*}{ cyclin dependent kinase 4} & GO:1904637 cellular response to ionomycin; 12-myristate \\
\hline & & GO:1904628 cellular response to phorbol 13-acetate \\
\hline & & GO:1904636 response to ionomycin \\
\hline \multirow[t]{3}{*}{ RPL23A } & \multirow[t]{3}{*}{ ribosomal protein L23a } & GO:0006614 SRP-dependent cotranslational protein targeting to membrane \\
\hline & & GO:0006613 cotranslational protein targeting to membrane \\
\hline & & hsa03010: Ribosome \\
\hline \multirow[t]{3}{*}{ XRCC6 } & \multirow[t]{3}{*}{ X-ray repair cross complementing 6} & GO:0075713 establishment of integrated proviral latency \\
\hline & & GO:0097680 double-strand break repair via classical nonhomologous end joining \\
\hline & & hsa03450: Non-homologous end-joining \\
\hline \multirow[t]{3}{*}{ EIF2S1 } & \multirow{3}{*}{$\begin{array}{l}\text { eukaryotic translation initiation factor } 2 \\
\text { subunit alpha }\end{array}$} & GO:1990737 response to manganese-induced endoplasmic reticulum stress \\
\hline & & GO:0032057 negative regulation of translational initiation in response to stress;process \\
\hline & & hsa04140: Autophagy - animal \\
\hline
\end{tabular}




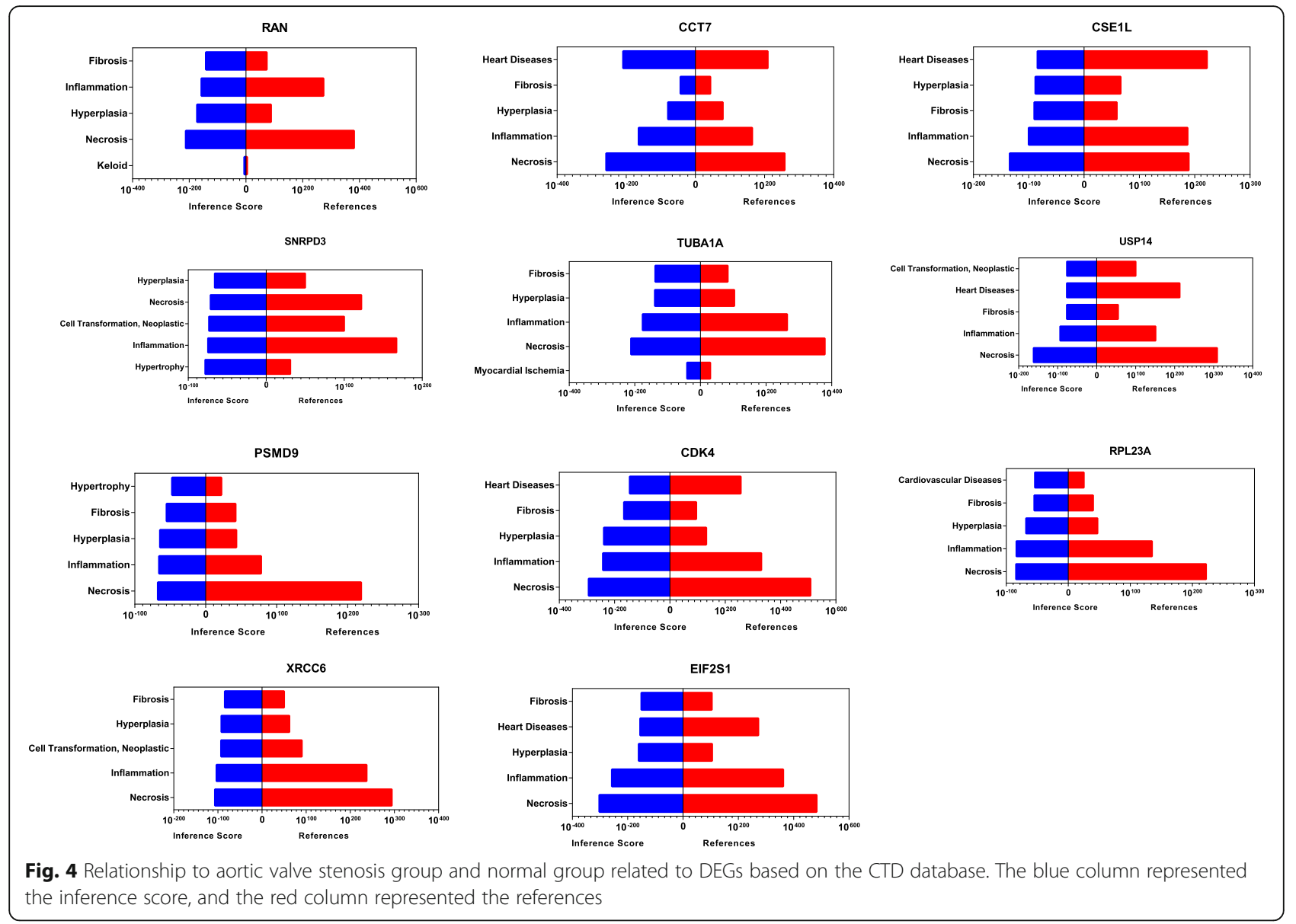

analyzed (Fig. 1f). The associations between clinical traits and the modules were identified based on the correlation between module and clinical traits (Fig. $1 \mathrm{~g})$. The heat map of the MEdarkgrey model DEGs' expression is shown in Fig. $1 \mathrm{~h}$.

\section{Functional and pathway enrichment analysis of DEGs}

GSEA to DEGs elicited an enrichment of the "heart process" and "cardiac muscle contraction" (Fig. 2a-b, Tables 4 and 5). Metscape analysis of DEGs showed an enrichment in the autophagy-animal, cellular lipid catabolic process, apoptosis, and glycoside metabolic process categories (Fig. 2c-e).

\section{Construction and analysis of the protein-protein interaction network}

The PPI network of the DEGs was constructed via the STRING online database and analyzed by Cytoscape software (Fig. 3a). Four different algorithms were employed to identify hub genes and 11 common hub genes were obtained (Fig. 3b). A summary of common hub genes is shown in Table 6. The PPI network of common hub genes is shown in Fig. 3c. The heat map of common hub genes is shown in Fig. 3d.

\section{Identification of hub genes}

The CTD database showed that common hub genes targeted heart diseases. It also highlighted pathophysiological processes such as fibrosis, inflammation, and necrosis, which are relevant in aortic stenosis pathogenesis (Fig. 4).

Table 7 A summary of miRNAs that regulate hub genes

\begin{tabular}{|c|c|c|c|c|c|}
\hline & Gene & Predicted MiR & & Gene & Predicted MiR \\
\hline 1 & RAN & $\begin{array}{l}\text { hsa-miR-489-3p } \\
\text { hsa-miR-324-5p } \\
\text { hsa-miR-205-5p }\end{array}$ & 7 & PSMD9 & $\begin{array}{l}\text { hsa-miR-532-5p } \\
\text { hsa-miR-9-5p } \\
\text { hsa-miR-30d-5p }\end{array}$ \\
\hline 2 & CCT7 & $\begin{array}{l}\text { hsa-miR-3607-5p } \\
\text { hsa-miR-3194-5p } \\
\text { hsa-miR-6858-3p }\end{array}$ & 8 & CDK4 & $\begin{array}{l}\text { hsa-miR-326 } \\
\text { hsa-miR-330-5p } \\
\text { hsa-miR-483-3p.1 }\end{array}$ \\
\hline 3 & CSE1L & $\begin{array}{l}\text { hsa-miR-6835-3p } \\
\text { hsa-miR-377-3p } \\
\text { hsa-miR-19b-3p }\end{array}$ & 9 & RPL23A & $\begin{array}{l}\text { hsa-miR-892c-5p } \\
\text { hsa-miR-506-5p } \\
\text { hsa-miR-6074 }\end{array}$ \\
\hline 4 & SNRPD3 & $\begin{array}{l}\text { hsa-miR-330-3p } \\
\text { hsa-miR-193a-3p } \\
\text { hsa-miR-193b-3p }\end{array}$ & 10 & XRCC6 & $\begin{array}{l}\text { hsa-miR-1207-3p } \\
\text { hsa-miR-7843-5p } \\
\text { hsa-miR-4632-5p }\end{array}$ \\
\hline 5 & TUBA1A & $\begin{array}{l}\text { hsa-miR-15b-5p } \\
\text { hsa-miR-497-5p } \\
\text { hsa-miR-424-5p }\end{array}$ & 11 & EIF2S1 & $\begin{array}{l}\text { hsa-miR-26a-5p } \\
\text { hsa-miR-26b-5p } \\
\text { hsa-miR-4465 }\end{array}$ \\
\hline 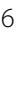 & USP14 & $\begin{array}{l}\text { hsa-miR-543 } \\
\text { hsa-miR-4429 } \\
\text { hsa-miR-320d }\end{array}$ & & & \\
\hline
\end{tabular}


Prediction and functional annotation of miRNA associated with hub genes

The miRNAs that regulate the hub genes were screened out with TargetScan (Table 7). GO and KEGG analyses of the miRNA were performed by DIANA-miRPath. GO and KEGG enrichment analysis to the screened miRNA demonstrated a preponderance of the cellular lipid metabolic process, apoptotic signaling pathway, nucleic acid binding transcription factor activity, toll-like receptor signaling pathway, Hippo signaling pathway, Arrhythmogenic right ventricular cardiomyopathy, and others (Fig. 5).

\section{Logistic regression analysis and identification of USP14}

The ROC curves of common hub genes are shown in Fig. 6. Likewise, the common hub genes and their effect on aortic stenosis, based on univariate logistic proportional regression analysis, are shown in Table 8 and those based on multivariate logistic proportional regression analysis in Table 9. Of the eleven potential biomarkers, USP14 was chosen, partly due to its higher odds radio (OR) calculated after multivariate logistic regression analysis (Table 9).

\section{Histological patterns of the aortic valve}

The HE staining demonstrated that the fibrous tissue and muscle cells were arranged regularly in the control aortic valve. However, the fibrous tissue and muscle cells were arranged irregularly in the aortic stenosis tissue (Fig. 7).

\section{The expression level of USP14 in the histology}

The immunohistochemistry assay manifested that USP14 was upregulated in the aortic stenosis tissues, compared with the control aortic valve (Fig. 8). Also, an immunofluorescence assay corroborated such finding (Fig. 9).

\section{Verification of the expression of USP14 in the mRNA and protein levels}

The RT-qPCR assay showed that the expression of USP14 was higher in the aortic stenosis than the control group $(P<0.05$, Fig. 10a). Moreover, in terms of the protein levels, the Western blotting confirmed that USP14

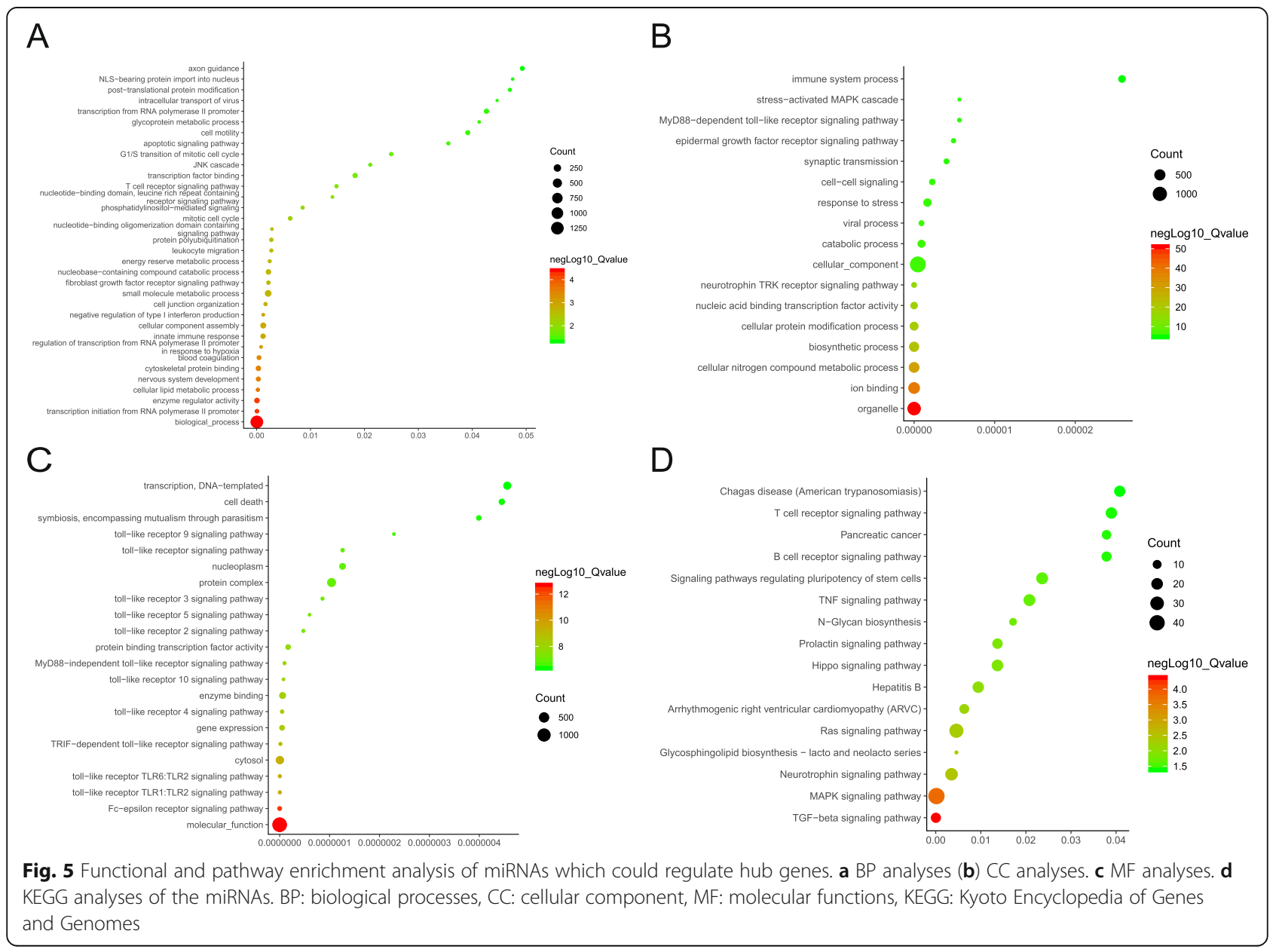




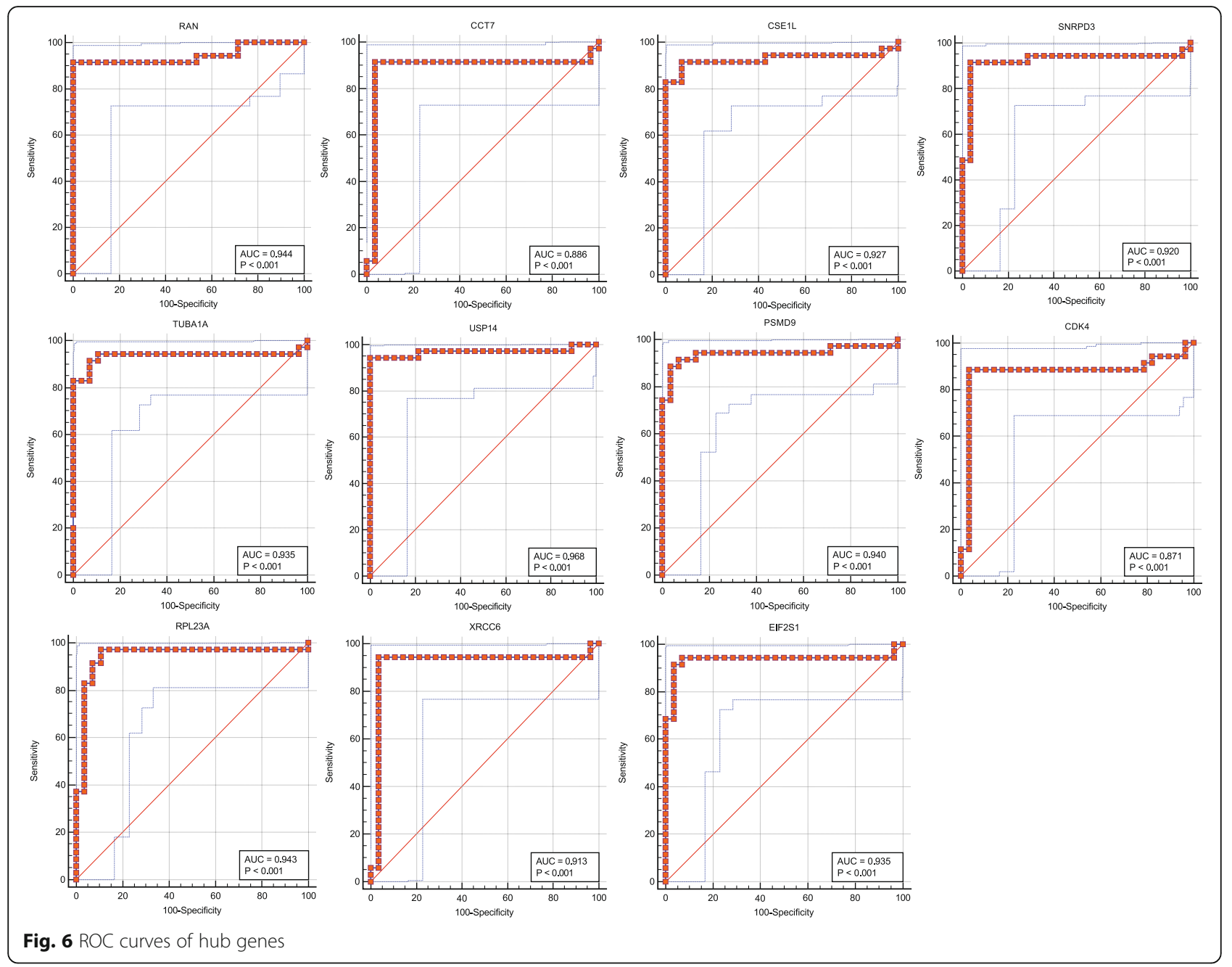

Table 8 The hub genes and their effect on aortic valve sclerosis based on univariate logistic proportional regression analysis

\begin{tabular}{llll}
\hline GENE & OR & $95 \% \mathrm{Cl}$ & $\mathrm{P}$ \\
\hline RAN & 1.044 & $1.025-1.063$ & .000 \\
CCT7 & 1.049 & $1.026-1.073$ & .000 \\
CSE1L & 1.118 & $1.064-1.175$ & .000 \\
SNRPD3 & 1.055 & $1.030-1.080$ & .000 \\
TUBA1A & 1.009 & $1.005-1.012$ & .000 \\
USP14 & 1.155 & $1.067-1.251$ & .000 \\
PSMD9 & 1.081 & $1.045-1.118$ & .000 \\
CDK4 & 1.063 & $1.031-1.096$ & .000 \\
RPL23A & 1.010 & $1.006-1.014$ & .000 \\
XRCC6 & 1.031 & $1.018-1.044$ & .000 \\
EIF2S1 & 1.079 & $1.046-1.113$ & .000 \\
\hline
\end{tabular}

was up-regulated in the aortic stenosis tissue compared with the control group (Figs. 10b, c). Western blotting corroborates immunohistochemistry and PCR findings.

\section{Discussion}

In this study, a WGCNA on microarray data from aortic valves predicted that USP14 would be highly expressed in the valves of aortic stenosis patients, which was effectively verified in molecular experiments with samples collected from patients. USP14 may become a target for the diagnosis and treatment of aortic stenosis.

Aortic stenosis, a progressive and chronic disease, is one of the most serious cardiac valvular diseases [11]. In

Table 9 The hub genes and their effect on aortic valve sclerosis based on multivariate logistic proportional regression analysis

\begin{tabular}{llll}
\hline GENE & OR & $95 \% \mathrm{Cl}$ & $\mathrm{P}$ \\
\hline USP14 & 1.236 & $1.043-1.464$ & .015 \\
XRCC6 & 1.033 & $1.005-1.062$ & .022 \\
\hline
\end{tabular}




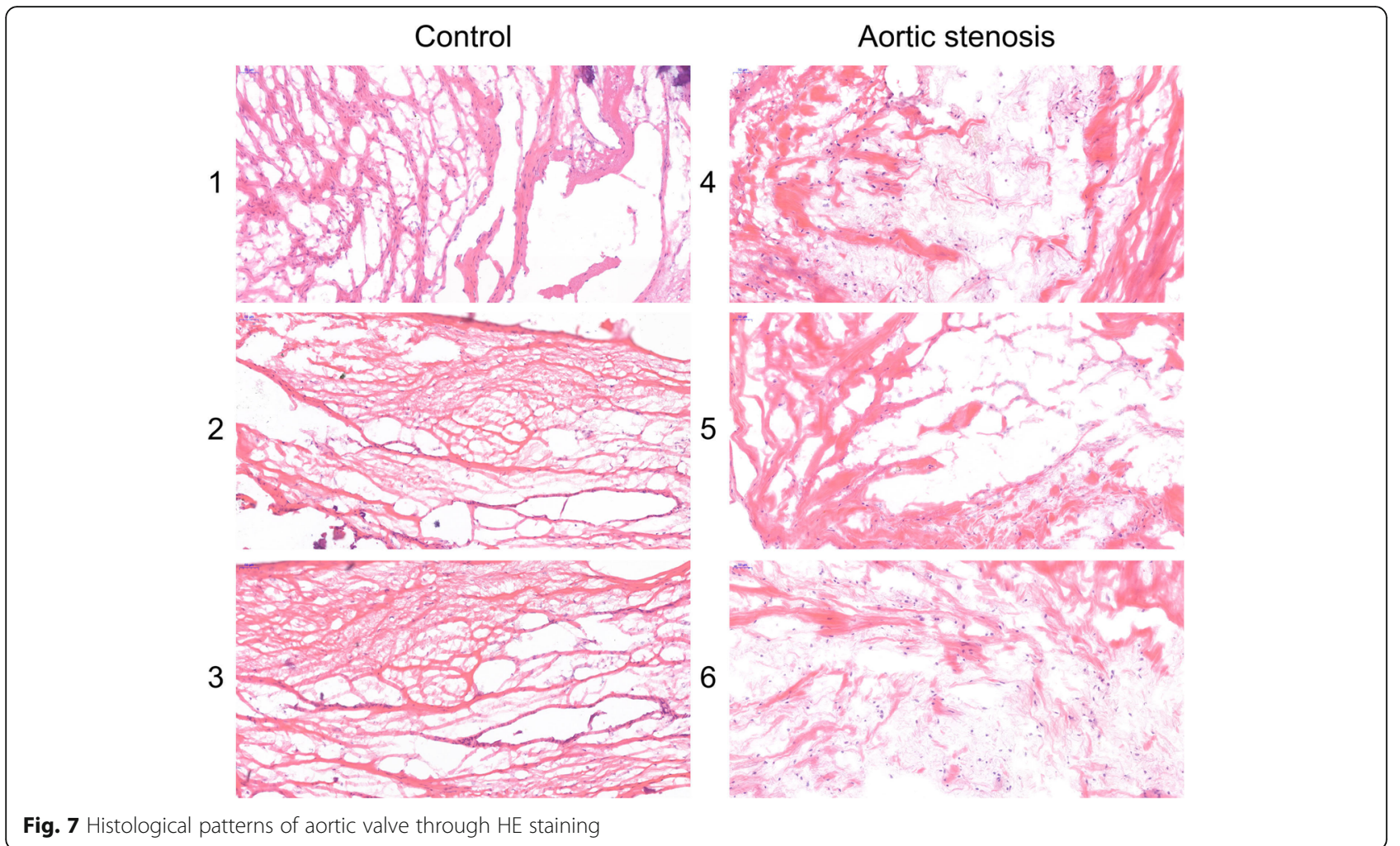

Fig. 7 Histological patterns of aortic valve through HE staining

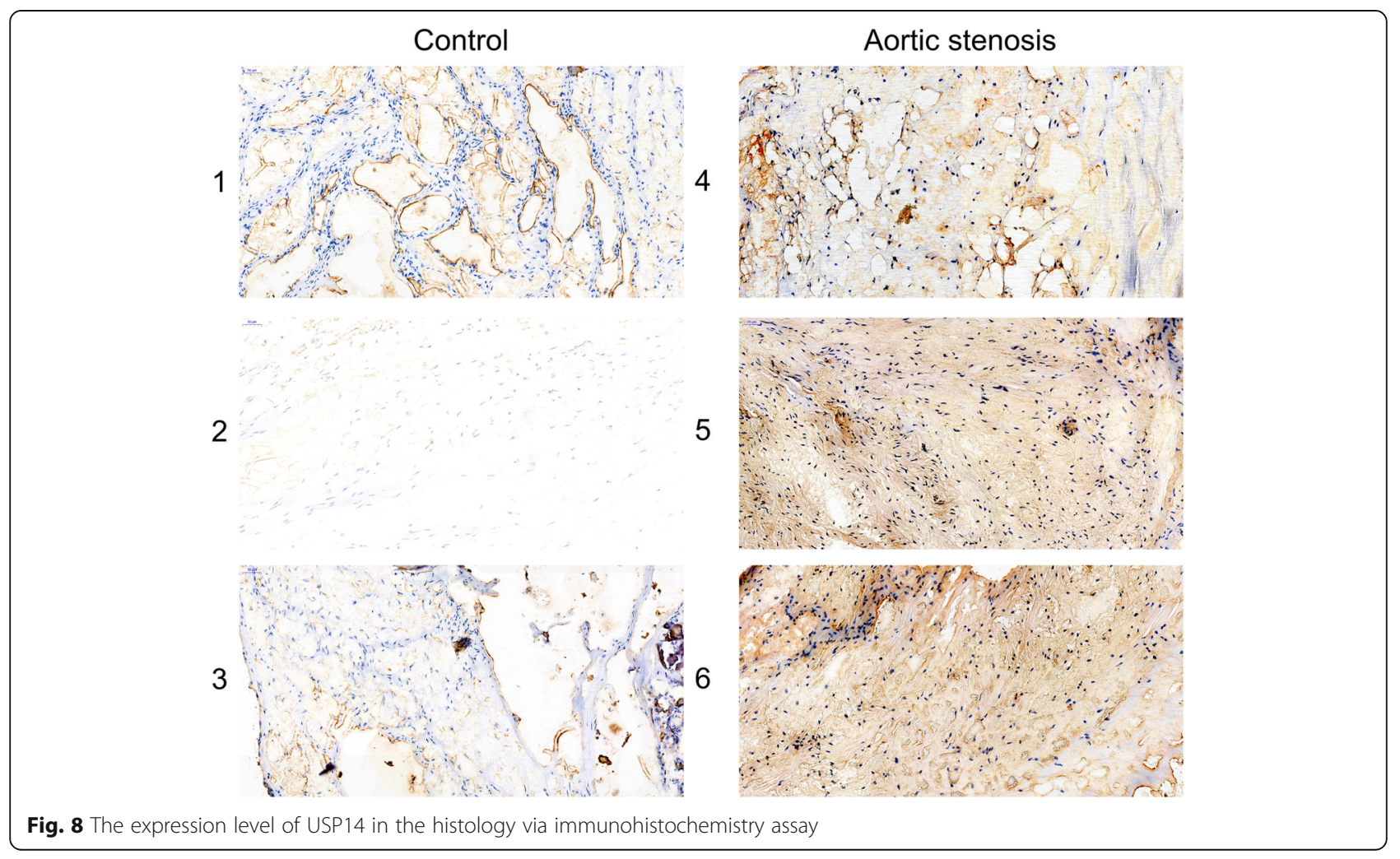




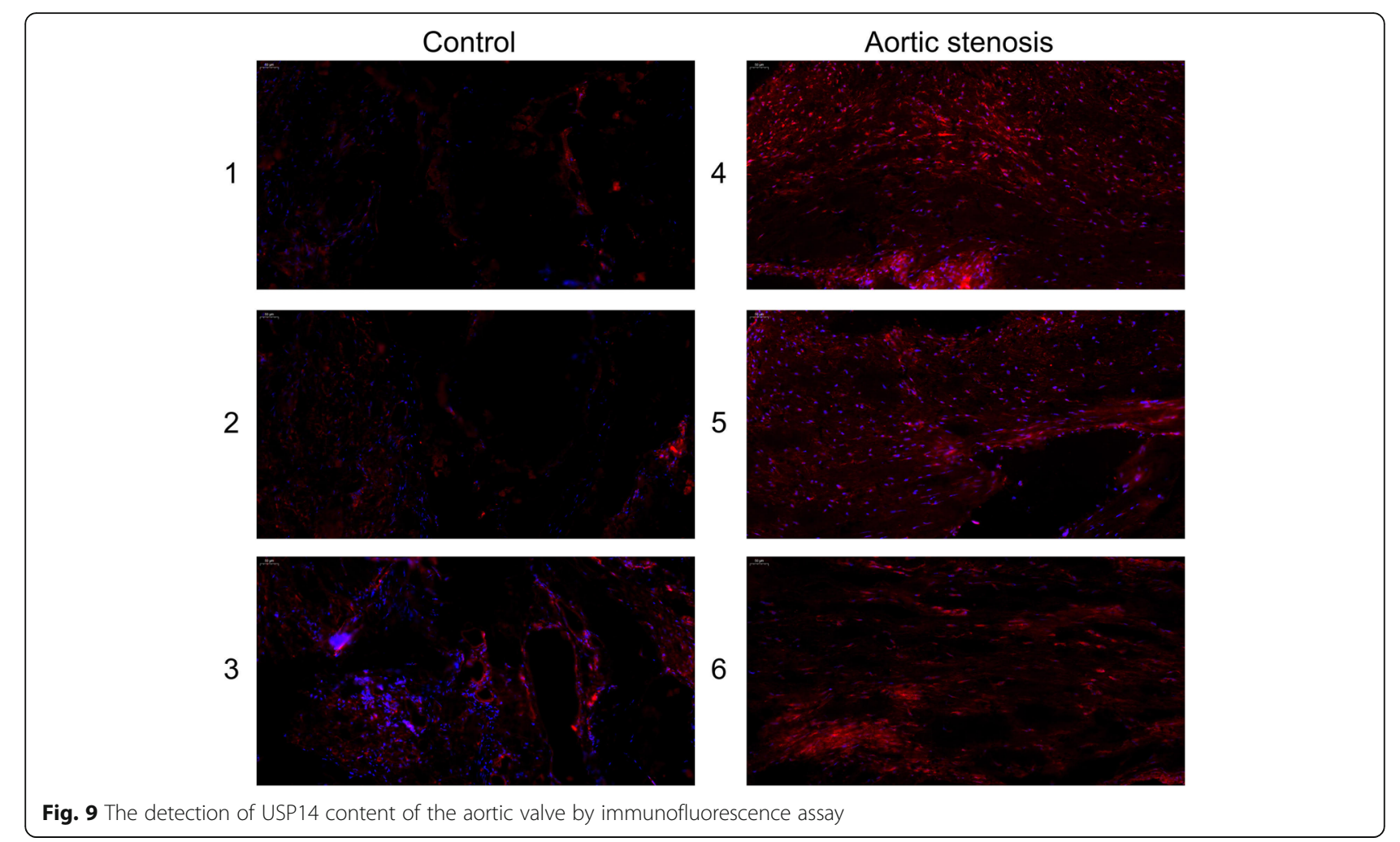

the sclerotic phase, aortic valves exhibit punctate calcification and valve thickening without hemodynamic changes and no obvious clinical symptoms, that is, aortic valve hardening. In the later stage, the valve ring and valve tissue appear to thicken, resulting in aortic valve stenosis and left ventricular outflow tract obstruction, which will eventually lead to serious obstruction of the left ventricular ejection function. The end stage of aortic stenosis is characterized by calcification, sided by the rupture of basement membranes, inflammatory cell infiltration, lipid deposition, endothelial dysfunction, and a series of activation processes caused by the transformation of valvular interstitial cells into osteoblasts [12].

USP14 is the only proteasome-binding deubiquitinating enzyme in the USP family. It can be recruited to $19 \mathrm{~s}$ particles to prevent it from being recognized and degraded by proteasome recognition, by cutting the ubiquitin chain on the protein substrate [13]. Accordingly, the inhibition of USP14 could improve the proteasome degradation activity [14]. USP14 is amplified and overexpressed in many types of diseases [15-18]. Overexpression of USP14 promotes cell proliferation and migration, while down-regulation induces cell apoptosis and inhibits cell proliferation, migration, and invasion. The expression of USP14 plays a pathogenic role in various types of diseases and is negatively correlated with the prognosis of the disease [19].
The coordination of the two reversible processes of ubiquitination and de-ubiquitination can finely regulate the type and degree of ubiquitination of proteins, affect the function and fate of corresponding proteins, and play an important role in many life activities such as cell division, differentiation, and signal transduction [20]. The USP14 protein has a total length of 494 amino acids and is divided into two domains: a ubiquitin-like domain (UBL) and a catalytic domain (CAT) [21]. It is one of the three deubiquitinating enzymes that bind to proteasome and can interact dynamically with proteins through ubiquitin. They regulate the function, metabolism, and degradation of proteins in the body, thus affecting a series of life activities such as the cell cycle, cell differentiation, transcription, DNA repair, immunity, and inflammation.

Dishevelled (Dvl) is a key regulator of Wnt signal transduction. USP14 can enhance the signal transduction of Wnt/ $\beta$-catenin. The inhibition of USP14 can also increase the degree of ubiquitination of Dvl and significantly inhibit the downstream of Wnt signal transduction [18]. Therefore, the consequence of $\mathrm{Wnt} / \beta$-catenin activation, due to USP14 Dvl de-ubiquitination, is that cell proliferation would be activated greatly, which would cause aortic valve hypertrophy and then lead to aortic stenosis. USP14 promotes the progression of cardiac hypertrophy by increasing GSK-3 $\beta$ phosphorylation 


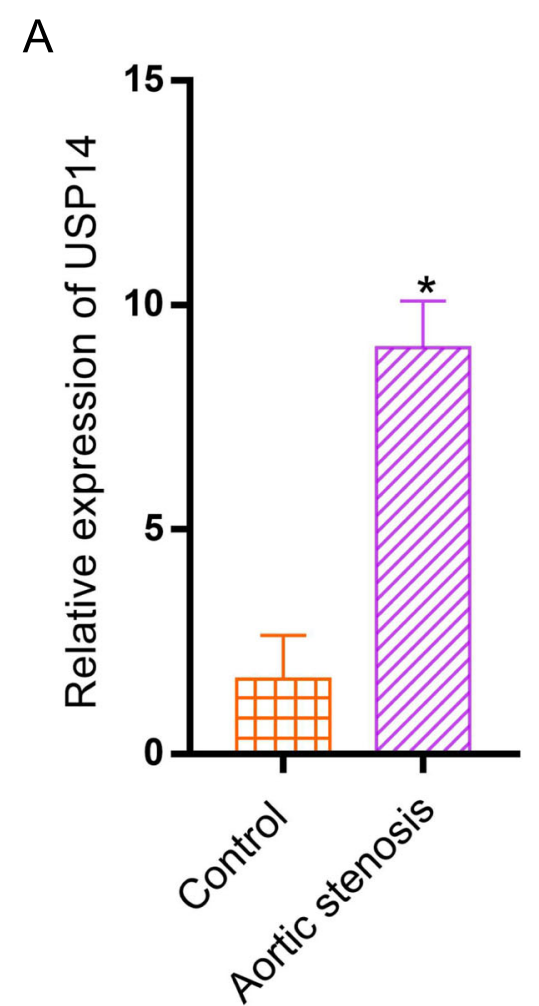

B

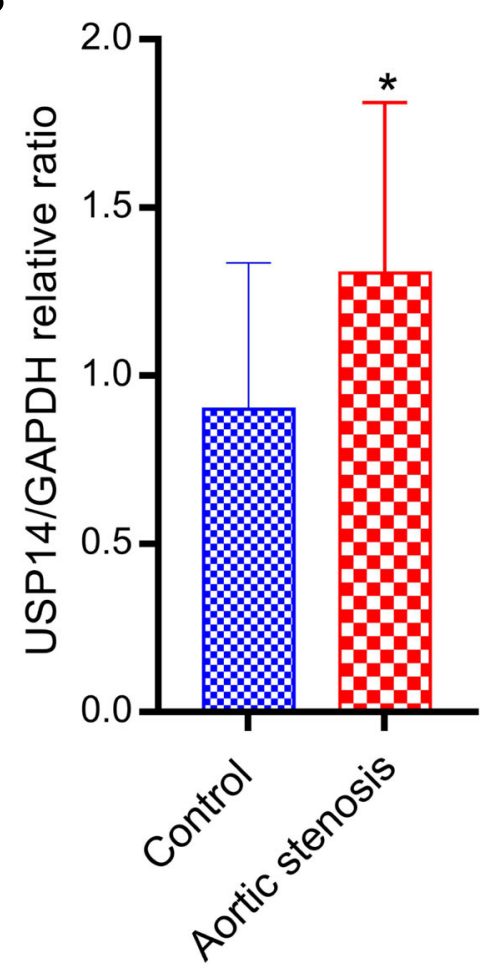

C Con AS Con AS Con AS
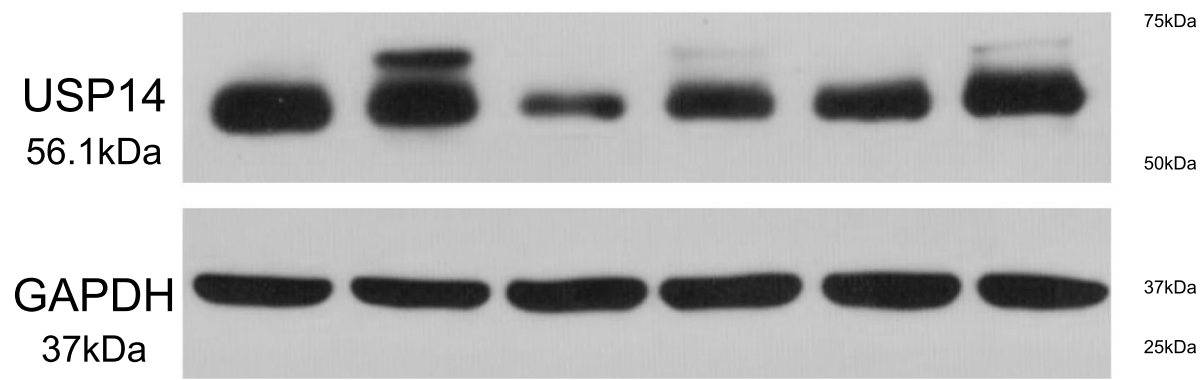

Con: Control; AS: Aortic stenosis

Fig. 10 Verification of the expression of USP14 in the mRNA and protein level. a Relative expression of USP14 by RT-qPCR analysis. ${ }^{*} p<0.05$, compared with control. b, c Western blotting expression of USP14 in the control and aortic stenosis groups

[22]. This study found that USP14 is highly expressed in aortic valve tissue, which inhibits the proteasome degradation activity so this research hypothesizes that the inflammatory factors and lipoproteins gathered in the aortic valve cannot be effectively degraded, resulting in aortic stenosis.

Many studies have shown that the development of aortic stenosis is similar to atherosclerosis, which is a lipid inflammatory process [23]. However, the nature of the specific endogenous stimuli triggering aortic stenosis is not yet clear. Excessive activation of macrophages plays a very important role in inflammatory diseases. Under the stimulation of inflammatory factors or bacteria, the activation of macrophages produces more inflammatory cytokines, causing a cascade of inflammation, which eventually becomes uncontrolled inflammation.

Nuclear factor- $\mathrm{kB}(\mathrm{NF}-\mathrm{kB})$ is an inducible transcriptional regulator of many inflammatory cytokine genes [24]. One study reported that overexpression of USP14 in lung epithelial cells can reduce ІкВ protein levels and increase cytokine release [25]. In addition, another study showed that USP14 affected NF- $\mathrm{kB}$ activation induced by lipopolysaccharide [26]. Based on these results, USP14 can induce the activation of NF- $\mathrm{KB}$ and regulate the up-regulation of tumor necrosis factor- $\alpha$ (TNF- $\alpha$ ), 
interleukin-6 (IL-6), and interleukin-18 (IL-18) expression by activating the NF- $\mathrm{BB}$ signal pathway. These inflammatory factors interact to form a positive feedback loop to increase the production of inflammatory factors, aggravating the inflammatory response in the valve, promoting lipid deposition, and ultimately promoting the occurrence of aortic stenosis.

\section{Strength and study limitation}

About the strength of the research, bioinformatics and clinical data were combined for analysis in this study. Many algorithms and experimental methods have been used to identify and verify the USP14 as an underlying gene biomarker for aortic stenosis. Although this study has carried out rigorous bioinformatic analysis, there are still some limitations. No animal experiments have been carried out. It is still necessary to further use an animal model to obtain more accurate results, in order to better understand the molecular mechanisms played by USP14 in aortic stenosis.

\section{Conclusions}

In summary, bioinformatics technology could be one useful tool to predict the progression of aortic stenosis, by exploring the mechanism of its occurrence and development. DEGs, especially USP14, might be involved in the occurrence and development of aortic stenosis and might eventually become a biomarker and a target to treat this disease. Detection of USP14 in the clinical practice might provide the better evidence to guide the early diagnosis and treatment of aortic stenosis. In the future, diagnostic reagent kit of USP14 and the corresponding drugs should be developed to perform the multicenter randomized controlled clinical trial.

\section{Abbreviations \\ GEO: Gene Expression Omnibus; DEGs: Differently expressed genes; WGCNA: Weighted gene co-expression network analysis; PPI: Protein-protein interaction; HE: Hematoxylin-eosin; RT-qPCR: Real time-quantitative polymer- ase chain reaction; USP14: Ubiquitin-specific protease 14; AS: Aortic stenosis; AVR: Aortic valve replacement; TAVI: Transcatheter aortic valve implantation; FC: Fold change; GO: Gene Ontology; BP: Biological processes; CC: Cellular components; MF: Molecular functions; KEGG: Kyoto Encyclopedia of Genes and Genomes; GSEA: Gene Set Enrichment Analysis; CTD: Comparative toxicogenomics database; ROC: Relative operating characteristic; OR: Odds radio; PBS: Phosphate buffer solution; DAB: Diaminobenzidine; GAPDH: Glyceraldehyde-3-phosphate dehydrogenase; SDS-PAGE: Sodium dodecyl sulfate polyacrylamide gel electrophoresis; PVDF: Polyvinylidene fluoride; UBL: Ubiquitin-like domain; CAT: Catalytic domain; Dvl: Dishevelled; NF-kb: Nuclear factor-kB; TNF-a: Tumor necrosis factor-a; IL-6: Interleukin-6; IL-18: Interleukin-18}

\section{Acknowledgements}

The authors are thankful to Ling-bing Meng for providing statistical assistance and suggestions during the submission process.

\section{Authors' contributions}

Yin Yang performed the experiments and were major contributors in the writing and submission of the manuscript. Zhi-gang Guo has made substantial contributions to the conception and design of the work. Bo-chen Yao designed the draft of the research process, and he was involved in interpretation of data. Lian-qun Wang was involved in revising the manuscript critically for important intellectual content, and he also made the analysis. Zhigang Guo analyzed the data. All authors read and approved the final manuscript.

\section{Funding}

Not applicable.

\section{Availability of data and materials}

The datasets used and/or analyzed during the current study are available from the corresponding author on reasonable request.

\section{Ethics approval and consent to participate}

The research conformed to the Declaration of Helsinki, and it was authorized by the Human Ethics and Research Ethics Committees of the Tianjin Chest Hospital. Informed consent was obtained from all the participants.

Consent for publication

Not applicable.

\section{Competing interests}

The authors declare that they have no competing interests.

Received: 1 February 2020 Accepted: 22 May 2020

Published online: 29 May 2020

References

1. Falk V, Baumgartner H, Bax JJ, De Bonis M, Hamm C, Holm PJ, lung B, Lancellotti P, Lansac E, Munoz DR, et al. ESC/EACTS guidelines for the management of valvular heart disease. Eur J Cardiothorac Surg. 2017; 2017(52):616-64.

2. Baumgartner H, Hung J, Bermejo J, Chambers JB, Evangelista A, Griffin BP, lung B, Otto CM, Pellikka PA, Quinones M. Echocardiographic assessment of valve stenosis: EAE/ASE recommendations for clinical practice. J Am Soc Echocardiogr. 2009;22:1-23 quiz 101-102.

3. Eveborn GW, Schirmer H, Heggelund G, Lunde P, Rasmussen K. The evolving epidemiology of valvular aortic stenosis. The Tromso study. Heart. 2013;99(6):396-400.

4. Kanwar A, Thaden JJ, Nkomo VT. Management of Patients with Aortic Valve Stenosis. Mayo Clin Proc. 2018;93(4):488-508.

5. Huntley GD, Thaden JJ, Alsidawi S, et al. Comparative study of bicuspid vS. tricuspid aortic valve stenosis. Eur Heart J Cardiovasc Imaging. 2018;19(1):3-8.

6. Patel A, Kirtane AJ. Aortic valve stenosis. JAMA Cardiol. 2016;1(5):623.

7. Joseph J, Naqvi SY, Giri J, Goldberg S. Aortic stenosis: pathophysiology, diagnosis, and therapy. Am J Med. 2017;130(3):253-63.

8. Meng LB, Shan MJ, Qiu Y, et al. TPM2 as a potential predictive biomarker for atherosclerosis. Aging (Albany NY). 2019;11(17):6960-82.

9. Meng LB, Yu ZM, Guo P, Wang QQ, Qi RM, Shan MJ, Lv J, Gong T. Neutrophils and neutrophil-lymphocyte ratio: inflammatory markers associated with intimal-media thickness of atherosclerosis. Thromb Res. 2018;170:45-52

10. Zhao Q, Li H, Chang L, Wei C, Yin Y, Bei H, Wang Z, Liang J, Wu Y. Qiliqiangxin attenuates oxidative stress-induced mitochondrion-dependent apoptosis in Cardiomyocytes via PI3K/AKT/GSK3beta signaling pathway. Biol Pharm Bull. 2019;42:1310-21.

11. Mathieu P, Despres JP, Pibarot P. The 'valvulo-metabolic' risk in calcific aortic valve disease. Can J Cardiol. 2007;23(Suppl B):32B-9B.

12. Osman L, Chester AH, Sarathchandra P, et al. A novel role of the sympathoadrenergic system in regulating valve calcification. Circulation. 2007;116(11 Suppl)::282-7.

13. Viguerie N, Tahiri-Jouti N, Esteve JP, et al. Functional somatostatin receptors on a rat pancreatic acinar cell line. Am J Phys. 1988;255(1 Pt 1):G113-20.

14. Lee $\mathrm{BH}$, Lee MJ, Park S, et al. Enhancement of proteasome activity by a small-molecule inhibitor of USP14. Nature. 2010;467(7312):179-84.

15. Huang G, Li L, Zhou W. USP14 activation promotes tumor progression in hepatocellular carcinoma. Oncol Rep. 2015;34(6):2917-24.

16. Liao Y, Xia X, Liu N, et al. Growth arrest and apoptosis induction in androgen receptor-positive human breast cancer cells by inhibition of 
USP14-mediated androgen receptor deubiquitination. Oncogene. 2018; 37(14):1896-910

17. Yu F, Liu JB, Wu ZJ, et al. Tumor suppressive microRNA-124a inhibits stemness and enhances gefitinib sensitivity of non-small cell lung cancer cells by targeting ubiquitin-specific protease 14 . Cancer Lett. 2018:427:74-84.

18. Jung H, Kim BG, Han WH, et al. Deubiquitination of Dishevelled by Usp14 is required for Wnt signaling. Oncogenesis. 2013;2:e64.

19. Zhu Y, Zhang C, Gu C, Li Q, Wu N. Function of Deubiquitinating enzyme USP14 as oncogene in different types of Cancer. Cell Physiol Biochem. 2016; 38(3):993-1002.

20. Haglund K, Dikic I. Ubiquitylation and cell signaling. EMBO J. 2005;24(19): 3353-9.

21. Wang $Y$, Jiang $Y$, Ding $S$, et al. Small molecule inhibitors reveal allosteric regulation of USP14 via steric blockade. Cell Res. 2018;28(12):1186-94.

22. Liu N, Chai R, Liu B, et al. Ubiquitin-specific protease 14 regulates cardiac hypertrophy progression by increasing GSK-3beta phosphorylation. Biochem Biophys Res Commun. 2016;478(3):1236-41.

23. Carita P, Coppola G, Novo G, et al. Aortic stenosis: insights on pathogenesis and clinical implications. J Geriatr Cardiol. 2016;13(6):489-98.

24. Hayden MS, Ghosh S. NF-kappaB, the first quarter-century: remarkable progress and outstanding questions. Genes Dev. 2012;26(3):203-34.

25. Mialki RK, Zhao J, Wei J, Mallampalli DF, Zhao Y. Overexpression of USP14 protease reduces I-kappaB protein levels and increases cytokine release in lung epithelial cells. J Biol Chem. 2013;288(22):15437-41.

26. Liu N, Kong T, Chen $X$, et al. Ubiquitin-specific protease 14 regulates LPSinduced inflammation by increasing ERK1/2 phosphorylation and NFkappaB activation. Mol Cell Biochem. 2017;431(1-2):87-96.

\section{Publisher's Note}

Springer Nature remains neutral with regard to jurisdictional claims in published maps and institutional affiliations.

Ready to submit your research? Choose BMC and benefit from:

- fast, convenient online submission

- thorough peer review by experienced researchers in your field

- rapid publication on acceptance

- support for research data, including large and complex data types

- gold Open Access which fosters wider collaboration and increased citations

- maximum visibility for your research: over $100 \mathrm{M}$ website views per year

At $\mathrm{BMC}$, research is always in progress.

Learn more biomedcentral.com/submissions 